\title{
What Makes Early Adults Feel Loved? Cultural Consensus of Felt Love Experiences in Early Adulthood
}

\author{
Olivia Ellis ${ }^{1}$, Saeideh Heshmati ${ }^{1}$, and Zita Oravecz ${ }^{2}$ \\ ${ }^{1}$ Department of Psychology, Claremont Graduate University \\ ${ }^{2}$ Human Development and Family Studies, Pennsylvania State University \\ ${ }^{2}$ Institute for Computational and Data Sciences, Pennsylvania State University
}

The manuscript is accepted for publication in the Journal of Applied Developmental Science.

\section{Author Note}

Olivia Ellis iD https://orcid.org/0000-0001-8621-9668

Saeideh Heshmati iD https://orcid.org/0000-0003-4002-128X

Zita Oravecz (iD https://orcid.org/0000-0002-9070-3329

We have no known conflict of interest to disclose.

Correspondence concerning this article should be addressed to Saeideh Heshmati,

Division of Behavioral and Organizational Sciences, Claremont Graduate University, 175 E. $12^{\text {th }}$ St., Claremont, CA 91711. Email: saida.heshmati@cgu.edu 


\begin{abstract}
The experience of love plays an integral role in human development as adolescents transition into adulthood. However, little is known about whether early adults have a shared understanding about indicators of love in daily life in this transitional phase. Using Cultural Consensus Theory informed by developmental theory, this study examined whether college-attending early adults in the United States reach a consensus on what makes people feel loved. One hundred sixty-six college-attending early adults ages 18 to 22 responded to 60 items on everyday scenarios and decided whether they thought most people would think each scenario was loving or not. Bayesian cognitive psychometric analysis revealed that college-attending respondents converged on a shared belief on love that included a wide range of everyday scenarios. Moreover, we found those higher conscientiousness and extraversion scores were more knowledgeable about the consensus on felt love. We expand on the developmental implications of these findings. Keywords: love, early adulthood, college students, personality styles, Cultural Consensus Theory, Bayesian analysis
\end{abstract}




\section{What Makes Early Adults Feel Loved? \\ Cultural Consensus of Felt Love Experiences in Early Adulthood}

The transitional period from adolescence to young adulthood (i.e., early adulthood) has been traditionally characterized as a gradual shift of focus from the self to connection with others. Early adults are heavily motivated to experience love and connectedness in this developmental stage (Dunkel \& Harbke, 2017; Erikson, 1950, 1959, 1968). In fact, feeling loved in daily life is found to be a central factor in their well-being network (Heshmati et al., 2020). However, love is a culturally-embedded experience (Heshmati et al., 2019): In order for an individual to successfully give and receive love, their beliefs on love need to be aligned with the cultural beliefs of their community (Heshmati \& Oravecz, 2021). Due to the central role that love and intimacy play in early adults' development, it is important to investigate whether early adults have formed beliefs on love and converge to a consensus on what love means and how it is experienced in daily life.

While most research on love in the early adult population has been focused on romantic ties, recently, research on love has been directed towards love as a momentary experience. Love can be conceptualized as an emotion - a micro moment of positivity resonance that can be experienced in a wide range of everyday life experiences (Fredrickson, 2016; Heshmati et al., 2019). For instance, snuggling up with a child, or even receiving care from a neighbor can be everyday life scenarios in which one can feel loved.

Research has shown that early adults in the United States often struggle with feeling loved (Noller et al., 2001; Reis et al., 2000). This challenge can become especially problematic for early adults who leave their homes and immediate families for the first time to relocate to college and a completely different environment. During this transition, they face an abrupt 
decrease in institutional support and an increase in challenges when adapting to a new social environment (Schulenberg et al., 2004). In industrialized countries such as the United States, institutional support is even further relaxed for college-attending early adults. This leads them to rely on their own abilities and skills to regulate their intimacy needs and create loving experiences in their day-to-day lives (Côté, 2000). In conjunction with decreased institutional support, college-attending early adults are choosing to delay life events such as marriage to prioritize work and school (Arnett, 2004). Yet, beliefs on love remain pertinent for collegeattending early adults (Dunkel \& Harbke, 2017). Thus, in this transitional phase, early adults begin to search for answers to questions such as "how can I feel more connected and loved?", "how can I make others feel more loved?", "what are the norms of the society that I live in about feelings of love?" These questions highlight the unique nature of the transition from adolescence to adulthood, in which identities are still developing while concerns about beliefs on love and intimacy arise (Montgomery, 2005).

\section{Love in Early Adulthood}

Love is considered the central theme in early adulthood. According to developmental theory, early adults' experiences of love and connectedness impact their transition to adulthood. Erikson's Psychosocial Theory of Development posits that development occurs in stages (Erikson, 1959), with each stage having its own crises needed to overcome. The transition to adulthood is marked with the crisis stage called intimacy versus isolation; individuals are challenged with whether they can form strong bonds and develop what Erikson refers to as the virtue of love or face isolation and loneliness (Erikson, 1950, 1959, 1968). Intimacy is viewed through a wide lens where individuals may form strong bonds through romantic partners or even friends. When people are able to form strong bonds with others during this stage, they gain the 
EARLY ADULTS AND CONSENSUS ON LOVE

virtue of love (Erikson, 1950, 1959, 1968). While Erikson's theory conceptualized feeling loved as an intimate bond between two people, recent research has expanded the conceptualization of feeling loved to experiences of positivity resonance that can occur on a momentary level in a wide range of contexts in everyday life (Fredrickson, 2016; Major et al., 2018). Hence, the urge for avoiding loneliness and feeling connected and felt love for early adults can be broader than relationship ties and can entail connecting with a community, a pet, or even nature (Heshmati et al., 2019).

Understanding beliefs on love becomes more relevant for the population of collegeattending early adults for two reasons: (1) they are in a developmental stage in which feeling loved and connected becomes central to their development and well-being (Erikson, 1959); (2) they transition from home -as a secure base - to a new environment with new social norms and conformities (Schulenberg et al., 2004). College-attending early adults spend a significant amount of time socializing and attending social events with peers $(\sim 3.5$ hours a day; Finlay, et al., 2012), yet many college students still suffer from loneliness. With a wide variety of opportunities to socialize at their fingertips, college students have more options than ever to connect and feel loved. While creating space for students to experience autonomy, the abundance of activities partnered with self-selecting career paths and social networks, can become debilitating for many (Schulenberg et al., 2004). These challenges, associated with entering into a new environment, can give rise to loneliness which is linked to depressive symptoms, drug usage, and even suicidal tendencies (Heshmati et al., 2021; Lamis, et al., 2014). Suicide rates as high as six to 12 percent for this population call for an examination of preventative measures for the feeling of loneliness and promotive factors of feeling loved (Arria et al., 2009; Heshmati et al., 2017; Lamis, et al., 2014; Oravecz et al., 2020; Wilcox et al., 2010). 
EARLY ADULTS AND CONSENSUS ON LOVE

\section{Scientific Conceptualizations of Love in Everyday Life}

Love has been challenging for researchers to conceptualize. Much of the delay in research on love has been attributed to the word previously being used loosely in the English language (Berscheid \& Meyers, 1996; Reis \& Aron, 2008) and descriptions of love not having had much of a common vocabulary (Rubin, 1998). Love is used in common vernacular associated with family or a romantic partner; it is also used to describe one's feelings toward a favorite food, a deity, or pets (Reis \& Aron, 2008). While research has approached love both in and out of the romantic context, there has been a call for more research understanding love in everyday life and contexts other than relationship ties (Heshmati \& Donaldson, 2020; Knox, 1970).

Everyday conceptions of love have been addressed from multiple viewpoints. The essentialist approach suggests love requires investing one's time in the well-being of another (Davis \& Todd, 1985). This tenet aligns with a more recently developed idea that love is a moment of positivity resonance in which two individuals share in mutual care/concern, positive emotion, and biobehavioral synchronicity (Fredrickson, 2016). In an attempt to further refine the conception of love, the prototype approach has allowed researchers to ask laypeople to describe features of love or a certain type of love in order to understand the phenomena in everyday life (Sternberg \& Sternberg, 2019). From this perspective, laypeople identified companionate types of love (e.g., familial, friendship, parental) as a more representative conceptualization of love in everyday life compared to a passionate type of love (e.g., romantic, passionate, etc.; Fehr, 1998; Sternberg \& Sternberg, 2019).

Most recently, building on prior research on laypeople's perception on love, Heshmati et al. (2019) introduced a new line of inquiry by examining beliefs on love in daily life in the 
Cultural Consensus Theory (CCT) framework (see, e.g., Batchelder et al., 2018; Romney et al., 1986). In this more broadly focused approach, felt love was thought of in terms of a communication process where loving signals are projected by a sender and the receiver interprets the signals as loving (or non-loving), leading to the receiver feeling loved (Oravecz et al., 2016). However, for signals to be interpreted as loving, they often require a consensus on the meaning of the signal. Heshmati et al. (2019) examined the cultural consensus on love in the US adult population (ages 18-93) and found there was a shared agreement on what everyday life scenarios were considered as loving and which ones were considered as non-loving. For example, simple daily scenarios such as "someone shows compassion towards them in difficult times." or "a child snuggling up to them" were agreed upon as loving by most of the sample. Moreover, overlaps in people's beliefs on love about themselves compared to their beliefs about others and the general consensus were significantly related to their psychological well-being (Heshmati \& Oravecz, 2021). Daily felt love dynamics have also been shown to be related to sleep quality (Dickens et al., 2021). Hence, the unique methodological approach of CCT that also examines love in a wide variety of everyday settings is a viable framework to assess beliefs on indicators of love.

\section{Cultural Consensus Theory in the Context of Love}

CCT is a methodologically sophisticated cognitive psychometric approach to understanding shared agreement on a content domain in a given culture. It has been used in social and behavioral sciences to study cultural belief and bias systems (for a summary, see, e.g., Weller, 2007). Additionally, CCT can quantify individual differences in the decision-making process that leads to the cultural consensus (see, e.g., Oravecz et al., 2015b). In CCT, culture is considered a group with common beliefs and/or shared knowledge (Romney, et al., 1986). Consensus refers to a shared agreement in beliefs or commonly held knowledge about a content 
domain in a culture. CCT is most useful when investigating whether a group shares an underlying belief on a concept regardless of whether there is an objective truth (Batchelder et al., 2012). With this approach, we can formally test whether a shared consensus exists in a culture, based on the responses of a representative sample. Second, we can determine where those agreements lie among the different beliefs, and the degree of consensus on each belief. Here, we used CCT to investigate whether a shared agreement exists regarding beliefs on love - as it manifests in daily life - among college-attending early adults in the United States, and what those daily scenarios might be.

When conducting CCT analysis, survey items need to be developed in a way that they represent reasonable indicators of the culturally shared belief or knowledge system (content validity). Moreover, these items do not ask about the preferences of an individual but operate on a more abstract level capturing the consensus views of the culture. For example, in the CCT framework individuals may be asked whether they believe the number of traffic accidents can be reduced by lowering speed limits, instead of being asked whether they often drive over the speed limit. When more people agree upon the same answer, it is more likely the answer will be reliable and valid in reflecting what a community believes (Weller, 2007). By deriving the consensus answers to these items, we can study what the consensus is on individual items. Moreover, by looking at the item difficulty level of the scenarios, we can also conclude how easy it is to know the consensus on each item, which reflects the level of agreement across the participants for each scenario (i.e., how strong the consensus is on it). Finally, we can also examine individual differences in decision-making characteristics and how they relate to personspecific variables such as personality, gender, and age. Applying a cultural consensus framework to study love is crucial since an objective truth most likely does not exist. 
EARLY ADULTS AND CONSENSUS ON LOVE

\section{Personality and Consensus on Love}

Personality has been considered a variable of interest in love research (Heshmati et al., 2019). In romantic relationships, high levels of extraversion and agreeableness have been associated with higher levels of love (Ahmetoglu et al., 2010; Asendorpf \& Wilpers, 1998; Schmitt et al., 2009). Individuals who have a more companionate view of love are higher in nurturance traits such as agreeableness. On the other hand, holding a more passionate view of love is related to low nurturance traits (Fehr \& Broughton, 2001). Personality continues to be germane when looking at daily experiences of love in consensus research (Heshmati et al., 2019; Oravecz et al., 2016). Heshmati et al. (2019) found that those higher in openness to experience were more likely to guess "True" when they were unsure of their response to the felt love items. However, individuals higher in agreeableness and/or neuroticism displayed more knowledge about the consensus of felt love (Heshmati et al., 2019). Associations between personality differences and love make personality a key variable to consider when assessing individual differences in decision-making characteristics regarding love and the consensus on love.

\section{The Current Study}

Numerous studies have aimed at conceptualizing love within relationship ties in the general population (Berscheid \& Walster, 1978; Hendrick \& Hendrick, 1986; 2006; Sternberg, 1986; 2006). However, there remains a gap in the literature in investigating love as a momentary experience of positivity resonance through a developmental framework and within specific daily contexts using a cultural consensus lens. The present study aims to fill this gap by considering beliefs on love in daily life from US college-attending early adults' perspective. We used the Felt Love Questionnaire (Heshmati et al., 2019) —including a wide range of everyday life scenarios with the potential of being loving - to gain a better understanding of whether college-attending 
early adults in the US come to a shared agreement on what love means. Specifically, using CCT, we explored the following questions in a college student population, 18 to 22 years old, in the United States: (1) Do college-attending early adults agree on what makes people feel loved? (2) If so, which scenarios are most highly agreed upon as loving? (3) Can person-specific characteristics such as personality traits, explain individual differences in decision-making styles and levels of knowledge on indicators of felt love? Individual differences in decision-making styles were quantified in terms of the following cognitive parameters: (1) willingness to guess the answer when respondents do not know the consensus (instead of marking "Don't know"), (2) guessing (acquiescence) bias, that is a tendency to guess true when uncertain, and the (3) level of consensus knowledge (i.e., cultural competence).

We hypothesized that college-attending early adults have developed beliefs on indicators of love in daily life. Loving experiences start out in a family context in early childhood and the search and exploration of loving experiences also begins around 13 years of age (Seiffge-Krenke, 2003). Thus, by early adulthood, individuals have developed their own beliefs on love and can gradually understand the shared beliefs on love, dominant in their culture. We also hypothesized that early adults high in agreeableness would have a greater ability to know the beliefs on love shared among this age group. Numerous studies have suggested an association between agreeableness and a greater understanding of love and behaviors often associated with love (Ahmetoglu et al., 2010; Heshmati et al., 2019; Schmitt et al., 2009). This may be due to agreeableness being associated with marital stability, relationship satisfaction, and other positive relationship characteristics (Karney \& Bradbury, 1995; Kwan et al., 1997; Shaver \& Brennan, 1992).

\section{Methods}




\section{Participants}

The study included 166 early adults aged 18 to 22 (106 women, $M_{\text {age }}=20.31$ years, $S D_{\text {age }}$ $=1.23$ years) from a public university in the NorthEast region of the United States. We used a convenience sampling method to recruit participants through the university's research website. Approximately $74 \%$ described themselves as White, 6\% as Black, 9\% as Asian or Pacific Islander, $4 \%$ as Hispanic Latino, and $1 \%$ as other races. Moreover, $59 \%(n=95)$ of the participants stated they were in a relationship, $40 \%(n=64)$ were single, and less than $1 \%(n=1)$ stated their relationship status was something other than being in a relationship and being single. This project was approved by The [blinded] Human Subjects Protection Program and IRB protocol number: STUDY00006362. Informed consent was obtained from all participants before they were involved in the study.

\section{Procedures}

During an in-person session in 2017, participants were asked to complete the 60 -item Felt Love Questionnaire and a battery of psychological tests and demographic questions administered on the web through Qualtrics (Qualtrics, Provo, UT). This session was the introductory session for a larger longitudinal study- data from which was not analyzed here.

\section{Measures}

\section{Demographics}

Questions were asked regarding gender, age, racial or ethnic group, relationship status (i.e. in a relationship, single, prefer not to answer, or other, please specify), and household members (i.e number of family members currently living in the same household, other than the participant). These demographic variables were included in order to get a more comprehensive understanding of whether each was related to people's decision-making characteristics. Apart 
from gender, race, and relationship status that have been selected as explanatory variables in previous studies on love and relationships (e.g., Heshmati et al., 2019), we also included household members to examine how living with others and having constant interactions with them might be related to people's knowledge about indicators of love. Multiple-choice format was used for each question with an option of "prefer not to answer" for most questions.

\section{Felt Love Questionnaire}

Participants were asked to respond to the prompt "most people feel loved when..." followed by 60 everyday life scenarios, with options "True", "False”, or "Don't know". The scenarios were derived from research and theories on love (Feeney, 2004; Fredrickson, 2013;

Gable et al., 2004; Hendrick \& Hendrick, 2006; Reis et al., 2004) as well as input from focus groups composed of laypeople. The resulting 60 items were validated in a large-scale study on a US representative sample by Heshmati et al. (2019). These items can be categorized into seven different themes: (a) trust and acceptance, (b) support in needs and goals, (c) symbolic or physical expressions, (d) sharing time with others, (e) other possible sources of love (e.g., gratitude, pets, nature, religion, etc.), (f) controlling/possessive items with a negative connotation, balancing out the positive scenarios, and $(\mathrm{g})$ neutral scenarios (e.g. "the sun is shining”) - this last group of items are counter-balancing the dominantly possibly loving items, but could also be used as an attention check to filter participants who would be responding "True" or "Don't know" to all items. Examples of scenarios in the questionnaire include "they feel accepted", "the sun is shining", and "someone tells them what is good for them". The Felt Love Questionnaire allows for the exploration of feeling loved in a general sense, asking participants to respond based on what "most people" believe, rather than inquiring about the 
participants' attitudes. This is in-line with the CCT approach to achieve an understanding of the shared knowledge of early adults and the beliefs they hold on love.

\section{Big Five Inventory-2}

Personality traits were quantified via The Big Five Inventory-2 (BFI-2; Soto \& John, 2017), which is a revision of the original Big Five Inventory (John, 1990). Soto and John (2017) developed and validated the BFI-2 over the course of 3 separate studies which highlighted the ability to maintain many of the strengths of the original measure such as the conceptual focus and ease of understanding, while strengthening predictive power, fidelity, providing greater bandwidth, and controlling for individual differences in acquiescent responding. For these reasons, we chose the BFI-2 because it encompassed the reliability and validity of the original inventory, while minimizing some of the prior inventory's limitations. On a scale of 1 (Disagree strongly) to 5 (Agree strongly), participants were asked the extent that they would disagree or agree with 60 statements. The statements begin with "I am someone who..." followed by characteristics such as "has an assertive personality" and "is outgoing, sociable." Based on how individuals report the extent of which they agree or disagree on each item, they are scored on the following five personality traits: extroversion (Cronbach's $\alpha=0.87$ ), agreeableness (Cronbach's $\alpha=0.76$ ), conscientiousness (Cronbach's $\alpha=0.85$ ), neuroticism (Cronbach's $\alpha=0.91$ ), and openness (Cronbach's $\alpha=0.83)$.

\section{Data Analysis}

We fit the Extended Condorcet Model in a multilevel Bayesian framework to the responses on the felt love items, while regressing individual differences in the decision-making characteristics on the above defined set of predictors. We examined whether early adults showed an agreement regarding beliefs on love via testing whether a single culture model can explain our 
data well (Weller, 2007). For this purpose, we calculated eigenvalues from the person-by-person correlation matrix of the participants' responses of the felt love items. These eigenvalues reflected the amount of variation accounted for by the first, second, and subsequent latent factors underlying the observed data (in a manner similar to a factor analysis).

The trichotomous response options of "True", "False", and "Don't know" allowed us to capture the decision-making process through the following person-specific parameters: ability to know the consensus, willingness to guess when the person does not know the consensus, and guessing bias towards responding "True" when uncertain. Figure 1 displays a processing tree depiction of the ECM (Heshmati et al., 2019) which is a visual representation of the decision process that yielded "True", "False", and "Don't know" responses. The cultural consensus is denoted by the top two branches of the tree and can either be "True" (loving) or "False" (nonloving). These labels are based on ECM estimates for each scenario. The subsequent branches stemming from the consensus answer indicate whether an individual knows the cultural consensus (thick branches leading to "True" and "False") or they do not know the answer (thin branches stemming from the consensus answer). If they do not know the consensus answer, they can either report that they "Don't know" the answer, or they may guess (displayed as "Willingness to guess"). The bottom branches display whether an individual will guess "True" or "False" when they do not know the answer. "Ability to know" represents the probability of a participant knowing the consensus answer. "Guessing bias" is the probability of guessing "True" when the person does not know the consensus answer. "Willingness to guess" is the probability of guessing instead of marking "Don't know."

\section{Figure 1}


EARLY ADULTS AND CONSENSUS ON LOVE

The Cognitive Processing Tree Representation of Decision-Making Processes in the Extended Condorcet Model

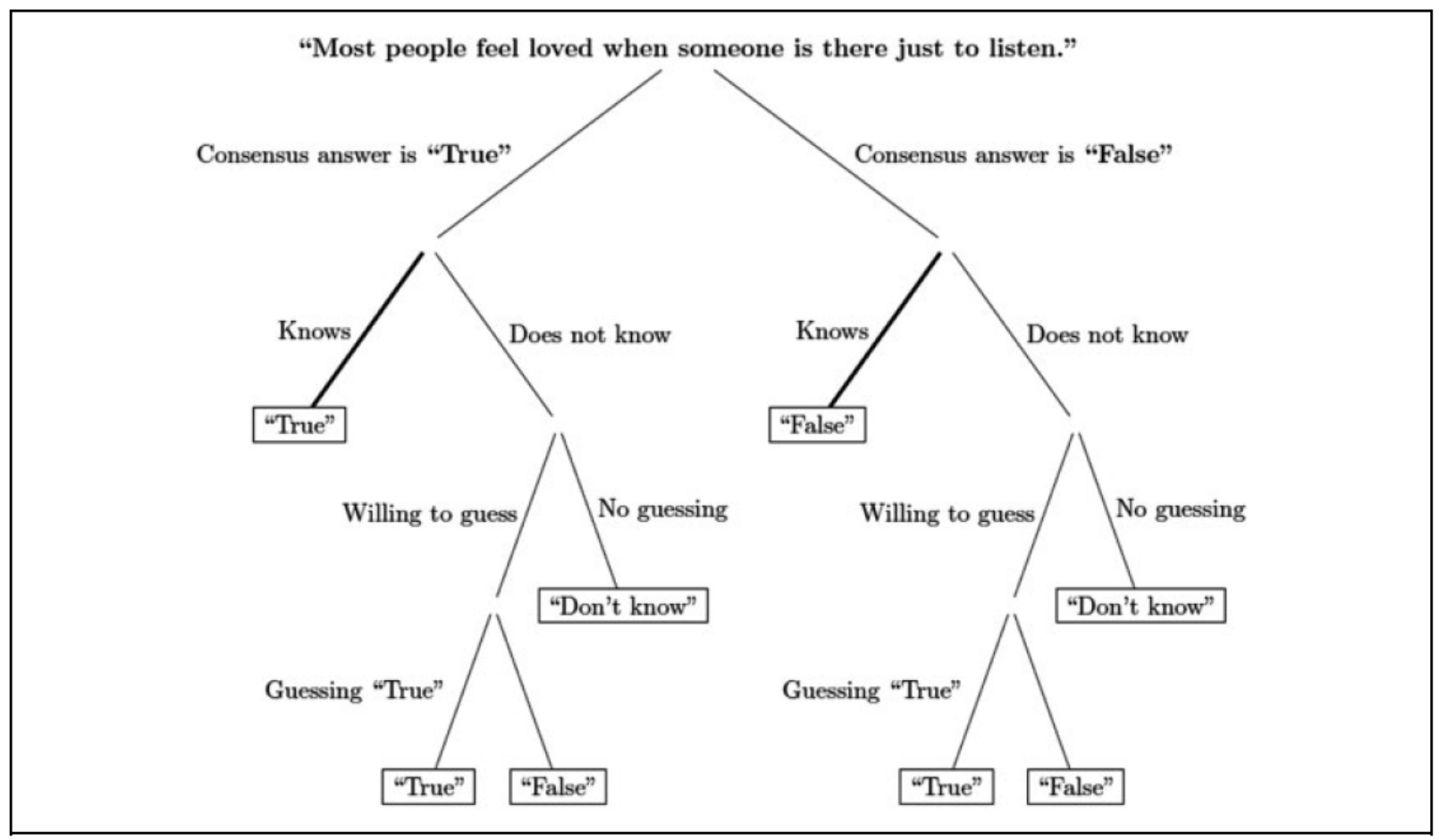

Note. Processing tree model for a single scenario on the felt love questionnaire based on the ECM.

The ECM parameters were estimated in the Bayesian statistical framework. In this framework all unknown model parameters are treated as random variables that have probability distributions (Gelman et al., 2013). This way the Bayesian approach allows for intuitive inference on the plausible range of parameters and uncertainty around point estimates. Moreover, Bayesian inference comes with powerful estimation approaches (i.e., Markov chain Monte Carlo algorithms) that make it possible to fit arbitrarily complex models. In our case the multilevel Bayesian (see, e.g., Gelman \& Hill, 2004) implementation for the ECM allowed for simultaneous estimation of all latent variables related to the decision-making and consensus judgment, as well as regression coefficients related to predictors. This means that the individual differences in the 
respondents' cultural competence levels weigh into deriving what the cultural consensus is, while at the same time the individual-specific competencies depend on the estimated consensus.

We regressed the three person-specific decision-making latent variables on the following individual predictors: gender, race, relationship status, age, household members, and personality style. Conducting this analysis in the Bayesian framework leads to posterior probability distributions for each regression coefficient. Posterior SD (or PSD) was calculated for each of the scenarios and when regressing the three person-specific decision-making variables on the aforementioned individual predictors. PSD summarizes the amount of uncertainty in the posterior estimates and can be considered as a Bayesian equivalent of the standard error. We used the posterior probability distribution of each regression coefficient for the decision-making variables and individual predictors to compute the lower and upper limit of a $95 \%$ credible interval - the true parameter value lies in this with $95 \%$ probability. The ECM also allowed us to investigate "Item difficulty", quantifying how hard it was for participants to know the consensus on each item.

The analysis was carried out in the Hierarchical Condorcet Modeling Toolbox (HCMT ${ }^{1}$; Batchelder et al., 2018), which is a user-friendly, graphical user interface-based software for fitting the ECM. It uses JAGS (Plummer, 2003) and MATLAB (MATLAB, 2010) to carry out Markov chain Monte Carlo (MCMC) sampling. During MCMC, an iterative model fitting procedure is performed to get parameter estimates. The number of iterations was chosen as 4,000 for the adaptation phase for the MCMC sampling, with an additional 10,000 iterations with 6 chains from which we calculated estimates, standard errors and credible intervals. For the model parameters to be reliably estimated, we checked for potential problems with convergence, using

\footnotetext{
${ }^{1}$ You can download the program from https://git.psu.edu/zzo1/HierarchicalCondorcetModeling Toolbox. It does not require a MATLAB license to use the program.
} 
a criterion of $\mathrm{R}<1.1$ (Gelman et al., 2013) and performed visual checks of the sample chains. The current analysis showed no problems with convergence. ${ }^{2}$

\section{Results}

\section{Early Adults Converge Toward a One-Culture Consensus on Love}

The observed data were well explained by a single-cultured consensus (i.e., one-factor solution). There was a sharp decline in eigenvalues from first to second, and subsequently a relatively flat line afterwards. Thus, our data suggested that early adults shared a single-cultured consensus about love.

\section{Felt Love Item Consensus Estimates for Early Adults}

Table 1 displays the results on all 60 felt love items, in terms of a raw data summary (True/False mean), the consensus estimates (Consensus label), uncertainty in these estimates in terms of posterior standard deviation (Posterior SD), as well as item difficulty ranks. The items in Table 1 are organized in descending order based on their True/False means. Items 1 through 52 had the consensus label of "True". The items closest to the top of the table had True/False ratios very close to one - these are the items that also had very high item difficulty ranks, meaning that they were easy items. The posterior SDs were very small, technically 0 for most items, indicating high certainty in the consensus estimates. Item numbers 1 and 2 ranked as the easiest to know the consensus for. These items included "someone cares for them when they are sick" and "they are made to feel special." The bottom of Table 1 (items 53 through 60) are items with the Consensus Labels of "False" - these are the items with the strongest consensus of the item being agreed upon as non-loving. Examples of these items include "someone is possessive about them" and "someone tells them what is best for them".

\footnotetext{
2 The data that support the findings of this study are openly available in the OSF website at https://osf.io/d8z4a/?view_only=23420bf5c72d4d79a333d5a934d18cfd.
} 
EARLY ADULTS AND CONSENSUS ON LOVE

Table 1

Raw Data Means and Estimates on Felt Love Items for Early Adults

\begin{tabular}{|c|c|c|c|c|c|c|}
\hline Category & $\begin{array}{l}\text { Item } \\
\text { Number }\end{array}$ & $\begin{array}{c}\text { Scenario } \\
\text { "Most people feel loved when..." }\end{array}$ & $\begin{array}{l}\text { True/False } \\
\text { Mean }\end{array}$ & $\begin{array}{l}\text { Consensus } \\
\text { Label }\end{array}$ & $\begin{array}{l}\text { Posterior } \\
\text { SD }\end{array}$ & $\begin{array}{l}\text { Item Difficulty } \\
\text { Rank }\end{array}$ \\
\hline B & 1 & someone cares for them when they are sick. & 1 & True & 0 & 60 \\
\hline A & 2 & they are made to feel special. & 1 & True & 0 & 59 \\
\hline $\mathrm{E}$ & 3 & their pets are happy to see them. & .99 & True & 0 & 58 \\
\hline B & 4 & $\begin{array}{l}\text { someone shows compassion towards them in } \\
\text { difficult times. }\end{array}$ & .99 & True & 0 & 57 \\
\hline B & 5 & someone is supportive of their life goals. & .98 & True & 0 & 56 \\
\hline $\mathrm{D}$ & 6 & $\begin{array}{l}\text { they spend time with their family (e.g., holidays, } \\
\text { vacation). }\end{array}$ & .98 & True & 0 & 46 \\
\hline A & 7 & $\begin{array}{l}\text { someone supports them without expecting anything } \\
\text { in return. }\end{array}$ & .98 & True & 0 & 55 \\
\hline $\mathrm{E}$ & 8 & they feel appreciated. & .97 & True & 0 & 54 \\
\hline A & 9 & they feel accepted. & .97 & True & 0 & 53 \\
\hline B & 10 & someone is there just to listen. & .97 & True & 0 & 52 \\
\hline $\mathrm{D}$ & 11 & they spend quality time with someone. & .97 & True & 0 & 49 \\
\hline B & 12 & someone calls just to check in on them. & .97 & True & 0 & 51 \\
\hline A & 13 & they feel completely comfortable around someone. & .97 & True & 0 & 47 \\
\hline $\mathrm{D}$ & 14 & they spend time with their child(ren). & .97 & True & 0 & 43 \\
\hline $\mathrm{C}$ & 15 & someone tells them: 'I love you'. & .96 & True & 0 & 50 \\
\hline A & 16 & someone understands them. & .96 & True & 0 & 48 \\
\hline B & 17 & $\begin{array}{l}\text { someone does something nice for them } \\
\text { unexpectedly. }\end{array}$ & .96 & True & 0 & 45 \\
\hline $\mathrm{C}$ & 18 & a child snuggles up to them. & .95 & True & 0 & 36 \\
\hline B & 19 & they experience an act of kindness. & .95 & True & 0 & 40 \\
\hline $\mathrm{C}$ & 20 & they are hugged. & .94 & True & 0 & 42 \\
\hline A & 21 & $\begin{array}{l}\text { they feel someone has no expectations and they can } \\
\text { be themselves. }\end{array}$ & .94 & True & 0 & 32 \\
\hline $\mathrm{C}$ & 22 & $\begin{array}{l}\text { when someone sends them signs of affection (e.g., } \\
\text { slight smile, loving glance). }\end{array}$ & .94 & True & 0 & 39 \\
\hline B & 23 & someone celebrates their accomplishments. & .93 & True & 0 & 44 \\
\hline $\mathrm{E}$ & 24 & they are recipients of gratitude. & .92 & True & 0 & 41 \\
\hline $\mathrm{D}$ & 25 & they have fun with their friends. & .92 & True & 0 & 38 \\
\hline $\mathrm{C}$ & 26 & they receive gifts (card, flowers etc.) & .92 & True & 0 & 35 \\
\hline $\mathrm{D}$ & 27 & they are included in activities. & .90 & True & 0 & 37 \\
\hline $\mathrm{C}$ & 28 & they are holding hands. & .89 & True & 0 & 31 \\
\hline
\end{tabular}


EARLY ADULTS AND CONSENSUS ON LOVE

\begin{tabular}{|c|c|c|c|c|c|c|}
\hline $\mathrm{E}$ & 29 & they feel connected to God. & .89 & True & 0 & 22 \\
\hline $\mathrm{C}$ & 30 & someone kisses them. & .89 & True & 0 & 34 \\
\hline $\mathrm{C}$ & 31 & they make love. & .89 & True & 0 & 26 \\
\hline A & 32 & they can share their opinions without being judged. & .88 & True & 0 & 29 \\
\hline A & 33 & $\begin{array}{l}\text { someone forgives them for something they did } \\
\text { wrong. }\end{array}$ & .87 & True & 0 & 28 \\
\hline B & 34 & someone helps them out. & .86 & True & 0 & 33 \\
\hline B & 35 & $\begin{array}{l}\text { someone follows up to ask how a problem turned } \\
\text { out. }\end{array}$ & .87 & True & 0 & 30 \\
\hline A & 36 & somebody confides in them. & .86 & True & 0 & 24 \\
\hline $\mathrm{D}$ & 37 & they feel part of a team. & .85 & True & 0 & 27 \\
\hline B & 38 & a group recognizes their contribution. & .84 & True & 0 & 25 \\
\hline B & 39 & they make up after a fight. & .83 & True & 0 & 20 \\
\hline $\mathrm{D}$ & 40 & they are around people, having fun. & .83 & True & 0 & 21 \\
\hline $\mathrm{C}$ & 41 & they receive a compliment. & .82 & True & 0 & 23 \\
\hline A & 42 & someone can immediately tell what is on their mind. & .81 & True & 0 & 19 \\
\hline B & 43 & something nice happens to them unexpectedly. & .73 & True & 0 & 18 \\
\hline $\mathrm{F}$ & 44 & someone insists to spend all of their time with them. & .72 & True & 0 & 17 \\
\hline $\mathrm{E}$ & 45 & they attend a religious ceremony. & 67 & True & 0 & 11 \\
\hline $\mathrm{C}$ & 46 & they get a compliment from a stranger. & .64 & True & 0 & 16 \\
\hline $\mathrm{C}$ & 47 & someone is sexually attracted to them. & .63 & True & 0 & 14 \\
\hline B & 48 & $\begin{array}{l}\text { someone gives them positive feedback on the } \\
\text { internet (e.g., a Facebook like, a retweet, etc.) }\end{array}$ & .61 & True & 0 & 13 \\
\hline $\mathrm{E}$ & 49 & they feel close to nature. & .58 & True & 0.22 & 7 \\
\hline $\mathrm{C}$ & 50 & someone is polite to them. & .56 & True & 0 & 12 \\
\hline G & 51 & the sun is shining. & .52 & True & 0.17 & 6 \\
\hline G & 52 & they eat their favorite food. & .51 & True & 0.22 & 4 \\
\hline $\mathrm{F}$ & 53 & $\begin{array}{l}\text { someone tries to change their behavior to be } \\
\text { healthier. }\end{array}$ & .43 & False & 0.27 & 5 \\
\hline $\mathrm{D}$ & 54 & they attend sporting events of their favorite team. & .42 & False & 0.40 & 2 \\
\hline $\mathrm{E}$ & 55 & they hear or sing their country's national anthem. & .41 & False & 0.47 & 3 \\
\hline $\mathrm{F}$ & 56 & $\begin{array}{l}\text { someone else wants to know where they are at all } \\
\text { times. }\end{array}$ & .38 & False & 0.28 & 9 \\
\hline $\mathrm{D}$ & 57 & they play sports. & .33 & False & 0.49 & 1 \\
\hline G & 58 & they solve a difficult problem. & .32 & False & 0.24 & 8 \\
\hline $\mathrm{F}$ & 59 & someone tells them what is best for them. & .31 & False & 0.19 & 10 \\
\hline $\mathrm{F}$ & 60 & someone is possessive about them. & .24 & False & 0 & 15 \\
\hline
\end{tabular}


Note. The first column displays the categories that each scenario belongs to: A) Trust and acceptance, B) Support in needs and goals, C) Symbolic/physical expressions, D) Sharing time with others, E) Other possible sources of love, F) Controlling behavior from others, and G) Neutral scenarios. The second column displays the mean value of the responses to each item with 'True' coded as 1 and 'False' coded as 0. True/False Means were hand calculated as a simple raw summary of the data. A True/False Mean closer to 1 translates to most people considering the item as loving (True). Items closer to 0 suggest that the item was perceived as not loving. Note that when True/False Means were calculated, the "Don't know" responses were ignored. PSD values close to 0 denote a high certainty in the estimates (strong consensus). PSD values farther from 0 indicate some degree of uncertainty in the estimate and suggest a less strong consensus (however, even in these cases consensus is reached, indicated by the eigenvalue test results and no problems with convergence on the parameter estimates). The items were ranked by difficulty in which the item ranked as a 1 would be considered the most challenging item. Only individuals with a high level of knowledge regarding the culture's consensus would be likely to know the answer. Conversely, scenarios with item ranks close to 60 are considered easy and even participants with relatively little knowledge of the consensus would likely answer them correctly.

In sum, items with highest agreement as loving among early adults were part of the following four themes of the Felt Love Questionnaire: (1) support in needs and goals, (2) trust and acceptance, (3) physical expressions of love, and (4) sharing time with others (for the purpose of feeling connected to something rather than simply attending an event). We also observed that early adults found scenarios centered on controlling and possessive behavior as non-loving. In what follows, we elaborate on the specific items representing each of these themes and the level of agreement on them.

First, early adults demonstrated the highest agreement that items centered on the "support in needs and goals" theme were loving. Examples of such items included: "someone cares for them when they are sick" (Consensus Label: True, PSD=0) and "someone shows compassion towards them in difficult times" (Consensus Label: True, PSD=0). These items also displayed a high certainty of estimates. Furthermore, these loving scenarios were not necessarily focused on romantic relationships; on the contrary, they were loving indicators that could be received from any relationship context, even pets. Interestingly, even the item "someone gives them positive feedback on the internet (e.g., a Facebook like, a retweet, etc.)" was agreed upon as loving by early adults (Consensus Label: True, $\mathrm{PSD}=0$ ) with high certainty.

Items centered on the "trust and acceptance" theme were also highly agreed upon as loving by early adults with a high certainty of estimates. Scenarios such as "they are made to feel special" (Consensus Label: True, $\mathrm{PSD}=0$ ), "someone supports them without expecting anything 
in return" (Consensus Label: True, PSD=0), and "they feel accepted" (Consensus Label: True, $\mathrm{PSD}=0$ ) were all highly agreed upon as loving.

Physical expressions of love were also highly agreed upon as loving with a high degree by early adults. In terms of physical expressions, "a child snuggles up to them" (Consensus Label: True, $\mathrm{PSD}=0$ ) was a highly agreed upon item and was considered the 36 th easiest item to know the consensus for. The item "they are hugged" (Consensus Label: True, PSD=0) was also agreed upon as loving and was ranked 42 nd in terms of item difficulty. Other physical expressions of love that were agreed upon as loving by young adults include "they are holding hands" (Consensus Label: True, PSD=0), “someone kisses them” (Consensus Label: True, $\mathrm{PSD}=0$ ), and "they make love" (Consensus Label: True, $\mathrm{PSD}=0$ ).

Items centered on "Spending time with others" were also agreed upon as loving. However, only items within this theme that denoted feeling connected to an entity or activity were highly agreed upon as loving as opposed to spending time with others by simply attending an activity or event. For example, "they feel connected to God" (Consensus Label: True, PSD=0) was highly agreed upon as loving compared to "they attend a religious ceremony" (Consensus Label: True, $\mathrm{PSD}=0$ ) for which people were more on the fence. While both are religious in nature and items had a strong certainty, the language of feeling "connected" versus "attending" connotes a different level of engagement. In a similar manner, "they feel part of a team" (Consensus Label: True, PSD=0) implies feeling more connected to the team, whereas "they attend sporting events of their favorite team" (Consensus Label: False, PSD=0.40), simply describes being in a team atmosphere at a sporting event which was not agreed upon as loving. Notably, being a part of a team had a strong consensus while attending the sporting event displayed that the certainty in the estimate was not as strong. 
The items that were most highly agreed upon as loving also had the highest item difficulty rank, meaning the items were the easiest. On the other hand, in the five items with the highest shared agreement that the items were non-loving, the items had a low item difficulty rank, meaning they were challenging to know the consensus for. The item "they play sports" was ranked as the most challenging item.

Notably, one theme that was prevalent among the "non-loving" scenarios was “controlling behavior." For example, "someone tells them what is best for them" (Consensus Label: False, PSD=0.19) and "someone else wants to know where they are at all times" (Consensus Label: False, PSD=0.28) are items that convey controlling behavior. A second central theme among the scenarios agreed as non-loving was individualized activities. Neutral items such as "They play sports" (Consensus Label: False, PSD=0.4904) and "they solve a difficult problem" (Consensus Label: False, PSD=0.24) were agreed upon as non-loving by early adults, with somewhat lower uncertainty in the consensus estimate. Both items could be interpreted as being centered on the person's own involvement in the activity as opposed to a team, which might be a reason why early adults did not see them as loving and in fact, regarded them as non-loving scenarios.

\section{Individual Differences in Early Adults' Shared Beliefs on Love}

Table 2 summarizes the assessed individual differences in decision making styles in relation to selected meaningful explanatory variables. Column 3 in Table 2 displays the regression coefficient (Mean) and column 4 displays the posterior standard deviation (PSD). The lower and upper limits of the $95 \%$ credible interval (CI) are noted in columns 5 and 6 . Results showed a meaningful positive association between ability to know the consensus and Conscientiousness $(M=0.20, S D=0.11)$ as well as Extraversion $(M=0.22, S D=0.10)$. In other 
EARLY ADULTS AND CONSENSUS ON LOVE

words, college-attending early adults in the United States that had a higher level of extraversion and those who were more conscientious were more likely to know the culture's shared consensus on what makes people feel loved. Additionally, we found a meaningful association between household members $(M=0.40, S D=0.18)$ and "guessing True". College-attending early adults with more household members are more likely to guess "True" when they do not know the answer. There was also a relationship between the tendency to respond "True" when unsure of the answer and age $(M=-0.12, S D=0.18)$. Those who were older were more likely to guess "True" when unsure of the answer.

Table 2

Summary of Selected Cognitive Individual Differences for Selected Explanatory Variables

\begin{tabular}{llcccc}
\hline Parameter & Predictor & Mean & PSD & LB of & UB of 95\% \\
& & & & $95 \%$ CI & CI \\
\hline Ability & Conscientiousness & $.20^{*}$ & .11 & .00 & .43 \\
& Extraversion & $.22^{*}$ & .10 & .03 & .42 \\
& Open Mindedness & .09 & .11 & -.19 & .31 \\
& Agreeableness & .15 & .10 & -.05 & .35 \\
& Neuroticism & -.09 & .10 & -.28 & .12 \\
& Gender & -.21 & .11 & -.44 & .00 \\
Age & .14 & .11 & -.06 & .36 \\
Household Members & -.06 & .11 & -.27 & .16 \\
& Relationship Status & .09 & .10 & -.11 & .29 \\
Race & -.13 & .10 & -.33 & .06 \\
Conscientiousness & -.44 & .24 & -.92 & .02 \\
Extraversion & -.15 & .23 & -.61 & .31 \\
Open Mindedness & -.13 & .25 & -.63 & .36 \\
Agreeableness & -.10 & .20 & -.60 & .20
\end{tabular}


EARLY ADULTS AND CONSENSUS ON LOVE

\begin{tabular}{|c|c|c|c|c|c|}
\hline & Neuroticism & .01 & .16 & -.33 & .31 \\
\hline & Gender & -.14 & .26 & -.64 & .02 \\
\hline & Age & -.08 & .24 & -.57 & .39 \\
\hline & Household Members & -.42 & .24 & -.90 & .04 \\
\hline & Relationship Status & -.04 & .23 & -.49 & .42 \\
\hline & Race & -.15 & .23 & -.60 & .30 \\
\hline Guessing "True" & Conscientiousness & .34 & .20 & -.12 & .71 \\
\hline & Extraversion & -.10 & .17 & -.43 & .23 \\
\hline & Open Mindedness & .05 & .17 & -.28 & .38 \\
\hline & Agreeableness & -.01 & .17 & -.34 & .32 \\
\hline & Neuroticism & .00 & .16 & -.33 & .31 \\
\hline & Gender & -.06 & .20 & -.44 & .40 \\
\hline & Age & -.12 & .18 & -.49 & .22 \\
\hline & Household Members & $.40^{*}$ & .18 & .06 & .76 \\
\hline & Relationship Status & -.17 & .16 & -.49 & .15 \\
\hline & Race & .07 & .16 & -.25 & .38 \\
\hline
\end{tabular}

Note. Estimates with an asterisk are meaningfully different from zero ( $95 \% \mathrm{CI}$ not containing 0 ). PSD= posterior standard deviation. LB stands for lower bound, UB for upper bound, CI stands for credibility interval.

\section{Discussion}

Considering the exploratory nature of this age group (Schulenberg, et al., 2004), their experience of instability (e.g., financially, work, housing; Goldscheider \& Goldscheider, 1999), and feelings of being in-between (Arnett, 2004), college-attending early adults in the United States might still be exploring their beliefs on love. Hence, through Cultural Consensus Theory in the current study we examined whether college-attending early adults in the United States have developed shared beliefs on love and if so, what might those beliefs be? Additionally, we also examined whether people with different personality styles demonstrate certain decision- 
making characteristics on the felt love items. Results were in line with our hypothesis that college-attending early adults (particularly 18-22 year olds) had developed shared beliefs on what comprises feeling loved on a daily basis and these beliefs are unique to their life experiences.

College attending early adults' beliefs on love encompass a wide range of everyday life settings. Notably, although our results support much of developmental theory and research focused on love in the context of relationships, findings however, reveal that interacting with someone is not a requirement for feeling loved for early adults. These results portray the breadth of daily scenarios that early adults may feel loved by that relationship scientists are likely to exclude in their assessments of love through merely focusing on love in romantic relationships or even relationships in general. Because we widened the scope in our examination and considered "love as a construct" that could result from any daily context, we were able to identify feeling loved from a lay perspective of early adults in a variety of contexts.

Some contexts that were agreed as loving were developmentally salient to this age group. Feeling accepted and special were highly agreed upon as loving, alluding to early adults' identity development and their need to feel belonging. Other contexts were specific to their lifestyle and the integration of technology and social media in their lives. For example, receiving positive feedback on the internet emerged as loving only for this population. Finally, contexts centered on showing care and compassion, such as someone caring for them when they are sick, describes the need for being cared for that is shared among people of all age groups.

The diversity in the range of contexts in which college-attending early adults agree upon as loving, depicts the vast array of ways that early adults can experience the feeling of love. Notably, these scenarios do not need the presence of a romantic interest. Hence, results of this 
study suggest a wider spectrum of sources that provide loving feelings for college-attending early adults — sources that could be considered attainable or valuable for this age range. Many of these sources of love may have been overlooked in previous research on love and neglected the developmental and contextual specificity of this population. In what follows, we discuss the emerging themes of the items that were agreed as loving by this population.

\section{Indicators of Love for Early Adults in Daily Life}

The scenarios that college-attending early adults agreed upon as loving were part of the following themes of the Felt Love Questionnaire: support in needs and goals, trust and acceptance, physical expressions of love, and sharing time with others especially when they felt connected to something rather than merely attending an event. As expected, controlling or possessive behavior (i.e., cases in which one feels controlled by another) were agreed as nonloving.

Out of all 60 scenarios, those centered around support in needs and goals including compassionate acts were the most highly agreed upon scenarios for college-attending early adults. For example, "someone cares for them when they are sick" and "someone shows compassion towards them in difficult times." and "someone is supportive of their life goals." were three scenarios centered on support and compassion that were strongly agreed upon as loving in this population. Compassion is a mode through which we see each other's suffering and extend a hand to show our care and support (Johnson, 2008; McConnell, 2015). The term compassionate love has been used to describe lending a hand to support another and can be experienced in a variety of relationship types including with family, friends, romantic interests, and peripheral ties (Neto \& Wilks, 2017; Sprecher \& Fehr, 2005). Compassionate and supportive acts were also highly agreed upon as loving for the general population (individuals ages 18 and 
older; Heshmati et al., 2019), implying that such acts might not be developmentally salient, rather an artifact of human nature constant across all life stages. When considering the developmental significance of compassionate and supportive acts specifically for early adults, parental support during identity development comes to the forefront for this age group. In this stage, early adults have some newly founded capabilities providing space for them to explore who they are, decide about goals, and examine where they fit in relation to others in the community (Benson, 2003; Damon, 2004; Lerner et al., 2009). During this particular stage they navigate the process of positive identity development (Eichas et al., 2014). In doing so, early adults engage in self-discovery and self-transformation. Adult support during this time has even been related to a successful transition to adulthood (Masten et al., 2004). Such characteristics of this age group may explain why daily scenarios centered on "support in needs and goals" become salient and agreed on as loving for early adults.

Another notable scenario within the support in needs and goals theme which was agreed as loving for college attending early adults was "someone gives them positive feedback on the internet (e.g., a Facebook like, a retweet, etc.)." This finding was unique to early adults (Consensus Label: True; PSD=0) since the general population did not agree that this scenario was loving (Heshmati et al., 2019). For early adults, positive feedback online may play a more significant role in their lives because of their greater internet usage (PEW, 2014). Additionally, online social media platforms have been identified as enticing methods for youth and early adults to feel connected (Lin \& Tsai, 2002; Tsai \& Lin, 2003) compared to other age groups. Because internet outlets may have a more significant role in early adults' lives, this can actually provide greater opportunities to create loving environments if used properly (Magis-Weinberg et al., 2021). 
Scenarios centered on trust and acceptance were a second set of items highly agreed upon as loving for early adults. For example, the scenarios "they are made to feel special" and "they feel accepted" are some of the scenarios that were highly agreed upon as loving. These results support the importance of early adults feeling accepted as they transition to a new college environment. Moving away from family to pursue college has been related to detrimental effects such as lower global self-esteem, however, peer acceptance has been shown to moderate this relationship (Birkeland et al., 2014). As such, peer acceptance has been shown to buffer the negative effects of being distant from family. Furthermore, previous research also suggests that trust beliefs are negatively associated with social and emotional loneliness for early adults (Rotenberg et al., 2010). Preventing loneliness becomes important when setting the stage for creating more loving moments (Erikson, 1959). Both studies highlight how trust and acceptance are developmentally significant for early adults and may contribute to making early adults feel loved.

A third group of items that were agreed upon as loving for early adults were centered around symbolic/physical expressions of love. Scenarios such as "someone tells them I love you," "a child snuggles up to them" and "they are hugged" are such examples that were agreed as loving. In general, receiving physical contact has been shown to promote physical, psychological, and relational well-being in adulthood (Jakubiak \& Feeney, 2016). Physical contact has also been associated with recruiting neural connections related to social cognition and reward on a broad level (Cascio et al., 2019). Developmentally, as adolescents transition to adulthood, physical contact continues to impact their cognition and how they behave (Cascio et al., 2019). Thus, physical contact has been related to various positive outcomes and has been linked to other concepts related to love (romantic and non-romantic) for early adults in 
particular, making scenarios related to physical contact agreed upon as loving for early adults. It is worthy of note that these scenarios, while agreed upon as loving, were not as highly agreed upon as scenarios centered on support in need and goals and trust and acceptance.

The fourth and final set of scenarios that that early adults agreed as loving was centered around the theme of spending time with others, especially if the scenario included feeling connected to an entity or activity as opposed to simply attending an activity. For example, the scenario "they feel part of a team" was agreed upon as loving by early adults, whereas "they attend sporting events of their favorite team" was not agreed upon as loving. "Feeling connected to God" was also more highly agreed upon as loving when compared to "they attend a religious ceremony." Although both scenarios are related to the same entity (i.e., Sports, God) the first connotes a sense or feeling of belonging and connectedness while the second suggests watching, attending, or being a bystander which does not necessitate connectedness or bonding. This aligns with research that states that humans have a fundamental need to belong- to interact and engage with those around them (Over, 2016). Because the transition to adulthood is especially marked with a desire to form strong bonds (Erikson, 1950, 1959, 1968), early adults may feel that loving moments involve the psychological connection and feeling of belonging rather than mere engagement or physical presence.

Notably, when looking further at the scenarios related to sports, the item "they play sports" was ranked as the most challenging item in terms of difficulty of the item. While this scenario was agreed upon as non-loving (Consensus=False, $\mathrm{PSD}=.49)$, it was also considered as the most challenging item to respond to for this population (item difficulty=1); in other words, only people who had high levels of knowledge about the consensus would be likely to know the answer to this item. This item was categorized as part of the "Sharing time with others" theme in 
the Felt Love Questionnaire. However, based on our observations, this scenario also does not connote actually feeling part of a team and is focused on the action of "playing" which might explain why the consensus was non-loving for early adults. The challenge in responding to the item may in fact be due to the dominant culture around sports in the US and especially in the college culture (Bryant \& Forsyth, 2005). Hence, while this item might not represent a scenario in which people would feel loved by, college-attending early adults may have ambivalent feelings about playing sports based on previous experiences. Perhaps for some, playing sports may bring about feelings of being accepted in the culture and belonging. In turn, this may have made them think twice about this item, whereas others not into the sport culture did not.

Early adults in the US also came to a consensus with fairly high agreement that scenarios centered around controlling and possessive behavior such as "someone tells them what is best for them" or "someone is possessive about them" are non-loving. Researchers state that the literature on controlling behaviors in adolescent and young adulthood populations is scant (Catallozzi et al., 2011). However, engaging in controlling behaviors is stated to peak in adolescence and then slowly decline throughout adulthood (Walker et al., 2017). Controlling behaviors are also indicative of unhealthy relationship patterns (Catallozzi et al., 2011; Elias-Lambert et al., 2014). Outside of romantic relationships, even controlling behaviors from maternal figures have been associated with negative outcomes such as lower emotion regulation in young adults (Manzeske \& Stright, 2009). When considering the aspect of culture, the individualistic culture of the United States also views control and constraint by others - regardless of the intent behind the action - as inhibition with a negative connotation. This is in contrast to communal cultures that view influence on behavior as extension of warmth and love for the other (Chen et al., 1998). This is developmentally salient because if controlling behaviors have been associated with a host of 
negative outcomes and early adulthood begins the period where intimacy is explored, then this understanding sets the tone for how they are navigating forming intimate bonds. These findings suggest that individuals even as young as college-attending early adults, have formed beliefs about controlling behaviors in interpersonal relationships being non-loving, which is also in line with the dominant cultures' beliefs around controlling behavior.

\section{Individual Differences in Decision-Making Styles}

CCT also allowed us to examine early adults' cognitive decision-making characteristics in the process of identifying scenarios that were loving or non-loving to them. In relation to their demographic background and personality characteristics, we assessed individual differences in their ability to know the consensus, their guessing bias, and their tendency to guess "True" when they were uncertain about the answer. Personality styles were meaningfully related to differences in these decision-making characteristics. Our hypothesis about early adults who are higher in agreeableness will have a greater ability to know the consensus on love was not supported; this finding was different from what was found previously for the general population (Heshmati et al., 2019), indicating a developmental significant to this finding. While previous studies have demonstrated that agreeableness is highly associated with love and loving behaviors (Ahmetoglu et al., 2010; Schmitt et al., 2009), this link may be due to the strong association between agreeableness and relationship stability (Karney \& Bradbury, 1995; Kwan et al., 1997; Shaver \& Brennan, 1992). In other words, people who are more agreeable tend to have more committed and stable relationships which in turn may lead to more knowledge of love and loving behavior in everyday life. In the case of college-attending early adults who are in an exploratory, this population is less likely to be in long-term commitments and relationships (Kuperberg \& Padgett, 2016), rather they tend to experiment with relationships and may be in an experimental 
phase to see what makes them feel loved and what doesn't. Hence, agreeableness in this population is not necessarily linked to higher knowledge of the consensus on love, perhaps due to this populations' less experience developing and maintaining long-term relationships. On the other hand, since the scenarios examined in this study were not all focused on relationships, in particular romantic ones, there may be other explanations for this finding. Developmental research has found that agreeableness is a trait that steadily increases across the lifespan (Donnellan \& Lucas, 2008). Thus, early adults may be lower in agreeableness as compared to older phases of adulthood, hence agreeableness may be less prevalent in this phase of life. This might be a potential reason why agreeableness does not play a big role in early adults' ability to know the consensus.

Instead, we found that conscientiousness and extraversion were related to higher ability to know the consensus on love (i.e., higher cultural competence on love). This finding is in line with previous research suggesting that low conscientiousness is associated with less awareness of others' emotional investments, or less awareness of loving actions and high conscientiousness is associated with intimacy and commitment (Ahmetoglu et al., 2010; Schmitt, 2004). Moreover, higher extroversion has also been associated with greater emotional investment (Schmitt et al., 2009). While both conscientiousness and extraversion have associations with relational or loving behaviors, they also are key for belief formation (Caspi et al., 2005; Klimstra, 2013; Soto, et al., 2011). Both extraversion and conscientiousness tend to increase with the emergence of an adultlike personality forming. Those more committed to forming an identity have displayed clear associations with conscientiousness as well (Klimstra, 2013; Lodi-Smith \& Roberts, 2007).

On the other hand, gender was not related to the ability to know the consensus which contrasted previous findings for the general population. A proposed reason for why men seemed 
to know less about the consensus compared to women for the general population but not for the early adulthood population could be due to the fact that women tend to have larger social networks as they age compared to men (Antonucci et al., 2014). For aging women, these larger social networks may provide more context as to what the general population views as loving.

Furthermore, those with more members in their household had a greater tendency to agree upon scenarios being loving (i.e., guess "True") when they were unsure of the answer. Early adults who live with a larger number of people in their household naturally have more interactions with family members/roommates in the house which could lead to more loving interactions in daily life while also being exposed to a wider variety of ways they would feel loved. Hence, they have a greater tendency to guess "true" as opposed to "false" or "don't know".

\section{Limitations and Future Directions}

This study was conducted on a college-attending sample of early adults in the United States. We acknowledge that although the focus was on the unique population of collegeattending early adults from one specific university in the United States, the study is limited to only reflecting the distinctive beliefs of this specific population. Future research may build on the current findings by expanding the sample to potentially other universities, non-collegeattending early adults, and also targeting populations outside of the United States to examine the universality of shared beliefs on love in this specific age group. Additionally, future examination of these beliefs on other developmental stages might open up a query in the field to examine love beyond romantic relationships with the consideration of one's stage of life.

Furthermore, our results suggest that college-attending early adults agree on the feeling of being connected to something larger than themselves as being loving. This is particularly 
interesting because it may not require any external influence to feel loved. For example, "they are hugged" (a scenario agreed upon as loving) requires someone else to be physically present, however "they feel part of a team" (also agreed upon as loving) does not require anyone else to be present, but rather focused on the feeling of belonging. Perhaps, feeling loved could be a result of reflecting or reframing a situation. Future research can consider using this in cognitive reframing interventions catered towards creating more feelings of love in early adults.

We also recognize that other predictors could play a role in the decision-making characteristics. The study shed light on how those with more members in their household were more likely to guess "True" when they did not know the answer, however, being in a relationship and number of siblings did not impact any of the decision-making characteristics. Although these results are informative, the question arises as to why there would be a difference in one's willingness to guess "True" between household members and siblings or being in a relationship. To better understand this relationship, future research should ask about the relationship between the participant and their household members (i.e. if the household members are siblings, parents, of potentially romantic partners). In addition to understanding the relationship to the participant, another area of exploration is to examine positivity resonance, or frequency of loving moments, as a potential predictor. In future research, other individual differences could also be studied for a potential impact on decision-making characteristics.

\section{Conclusion}

The present study contributed to our understanding on how early adults think about love, whether they have developed shared beliefs on love, and whether their beliefs are specific to their developmental stage. This study was unique in several ways. We considered love as a construct, rather than love as a relationship tie (see Heshmati \& Donaldson, 2020 for 
comparisons). This approach allowed us to examine felt love in contexts beyond relationships and in everyday life situations. Additionally, we took a CCT perspective that allowed us to examine college-attending early adults as a group that formed their own "culture." CCT also provided tools for us to take a bottom-up approach to understand feeling loved from layperson's perspective.

Based on the results, we conclude that feeling loved for college-attending early adults can happen in a wide variety of everyday life scenarios that go beyond relationship contexts. We also conclude that while feeling loved can occur in contexts that are shared across all age groups, there are also loving everyday life contexts that are developmentally salient to early adults and are contextually specific to their generation and lifestyles.

These results open up a new avenue in understanding love and beliefs around situations that make people feel loved, specific to college attending early adults, that was not previously explored. While much of the conversation regarding love in this particular age group has primarily focused on relationships (Erikson, 1959), the results shed light on an opportunity to support this population in feeling loved even when close others are not present- which is the case for many early adults transitioning into a new lifestyle and college environment. For collegeattending early adults, these findings create hope for future interventions that can help minimize the feeling of loneliness and create more opportunities for them to feel loved. Additionally, these results provide a practical guide for intervention scientists and practitioners specialized in the well-being of early adults to provide developmentally-relevant and contextually-sensitive practices for this population to feel loved, including a wide variety of experiences that are not necessarily limited to relational contexts. 


\section{References}

Ahmetoglu, G., Swami, V., \& Chamorro-Premuzic, T. (2010). The relationship between dimensions of love, personality, and relationship length. Archives of Sexual Behavior, 39, 1181-1190. http://doi.org/10.1007/s10508-009-9515-5

Antonucci, T. C., Ajrouch, K. J., \& Birditt, K. S. (2014). The convoy model: Explaining social relations from a multidisciplinary perspective. The Gerontologist, 54(1), 82-92. https://doi.org/10.1093/geront/gnt118

Arnett, J. (2000). Emerging adulthood: A theory of development from the late teens through the twenties. The American Psychologist, 55(5), 469-80. http://doi.org/10.1037/0003066x.55.5.469

Arnett, J. J. (2004). Young adulthood: The winding road from the late teens through the twenties. New York: Oxford University Press.

Arnett, J. (2007). Afterword: Aging out of care-Toward realizing the possibilities of emerging adulthood. New Directions for Youth Development, 2007(113), 151-161. https://doi.org/10.1002/yd.207

Arria, A. M., O’Grady, K. E., Caldeira, K. M., Vincent, K. B., Wilcox, H. C., \& Wish, E. D. (2009). Suicide ideation among college students: A multivariate analysis. Archives of Suicide Research, 13, 230-246. https://doi.org/10.1080/13811110903044351

Asendorpf, J. B., \& Wilpers, S. (1998). Personality effects on social relationships. Journal of Personality \& Social Psychology, 74(6). https://doi.org/10.1037/0022-3514.74.6.1531

Batchelder, W. H., \& Anders, R. (2012). Cultural Consensus Theory: Comparing different concepts of cultural truth. Journal of Mathematical Psychology, 56, 316-332. https://doi.org/10.1016/j.jmp.2012.06.002 
Batchelder, W. H., Anders, R., \& Oravecz, Z. (2018): Cultural Consensus Theory. In Eric-Jan Wagenmakers \& John T. Wixted (Eds.), The Stevens' Handbook of Experimental Psychology and Cognitive Neuroscience, 5(4), 221-264. New York, NY: John Wiley \& Sons.

Batchelder, W. H., \& Romney, A. K. (1988). Test theory without an answer key. Psychometrika, 53, 71-92. https://doi.org/10.1007/BF02294195

Bell, R. A., \& Roloff, M. E. (1991). Making a love connection: Loneliness and communication competence in the dating marketplace. Communication Quarterly, 39(1), 58-74. https://doi.org/10.1080/01463379109369783

Benson, P. L., \& Scales, P. C. (2009). The definition and preliminary measurement of thriving in adolescence. The Journal of Positive Psychology, 4(1), 85-104. http://doi.org/10.1080/ $\underline{17439760802399240}$

Berscheid, E., \& Meyers, S. A. (1996). A social categorical approach to a question about love. Personal Relationships, 19-43. https://doi.org/10.1111/j.1475-6811.1996.tb00102.x

Berscheid, E., \& Walster, E. (1978). Interpersonal attraction (2 ${ }^{\text {nd }}$ ed.). Mass: Addison-Wesley. Beyers, W., \& Seiffge-Krenke, I. (2010). Does identity precede intimacy? Testing Erikson's theory on romantic development in young adults of the $21^{\text {st }}$ century. Journal of Adolescent Research, 25(3), 387-415. https://doi.org/10.1177/0743558410361370

Birkeland, M. S., Breivik, K., \& Wold, B. (2014). Peer acceptance protects global self-esteem from negative effects of low closeness to parents during adolescence and early adulthood. Journal of Youth and Adolescence, 43(1), 70-80. https://doi.org/10.1007/s10964-013-9929-1 
EARLY ADULTS AND CONSENSUS ON LOVE

Bryant, C. D., \& Forsyth, C. J. (2005). The fun God: Sports, recreation, leisure, and amusement in the United States. Sociological Spectrum, 25(2), 197-211. https://doi.org/10.1080/02732170590884059

Cascio, C. J., Moore, D., \& McGlone, F. (2019). Social touch and human development. Developmental Cognitive Neuroscience, 35, 5-11. https://doi.org/10.1016/j.den.2018.04.009

Caspi, A., Roberts, B. W., \& Shiner, R. L. (2005). Personality development: Stability and change. Annual Review of Psychology, 56, 453- 484. https://doi/10.1146/annurev.psych.55.090902.141913

Catallozzi, M., Simon, P., Davidson, L., Breitbart, V., Rickert, V. (2011). Understanding control in adolescent and young adult relationships. Archives of Pediatric Adolescent Medicine, 165, 313-319. http://doi.org/10.1001/archpediatrics.2011.32

Chen, X., Hastings, P. D., Rubin, K. H., Chen, H., Cen, G., \& Stewart, S. L. (1998). Childrearing attitudes and behavioral inhibition in Chinese and Canadian toddlers: A crosscultural study. Developmental Psychology, 34(4), 677-86. https://doi.org/10.1037/0012$\underline{1649.34 .4 .677}$

Chopik, W. J., \& Kitayama, S. (2018). Personality change across the lifespan: Insights from a cross-cultural longitudinal study. Journal of Personality, 86(3), 508-521. https://doi.org/10.1111/jopy.12332

Côté, J. E. (2000). Arrested adulthood: The changing nature of maturity and identity. New York: New York University Press.

Csikszentmihalyi, M., \& Csikszentmihalyi, I. S. (2006). A life worth living: Contributions to positive psychology (Ser. Series in positive psychology). Oxford University Press. 
EARLY ADULTS AND CONSENSUS ON LOVE

Damon, W. (2004). What is positive youth development? The Annals of the American Academy of Political and Social Science, 591(1), 13-24. https://doi.org/10.1177/ $\underline{0002716203260092}$

Davis, K. E., \& Todd, M. J. (1985). Assessing friendship: Prototypes, paradigm cases and relationship description. In S. Duck \& D. Perlman (Eds.), Understanding personal relationships: An interdisciplinary approach (pp. 17-38). Sage Publications, Inc.

Dickens, C. N., Gray, A. L., Heshmati, S., Oravecz, Z., \& Brick, T. R. (2021). Daily implications of felt love for sleep quality. The American Journal of Psychology, 134(4), 463-477. https://doi.org/10.5406/amerjpsyc.134.4.0463

Donnellan, M. B., \& Lucas, R. E. (2008). Age differences in the Big Five across the life span: evidence from two national samples. Psychology and aging, 23(3), 558-566. https://doi.org/10.1037/a0012897

Dunkel, C., \& Harbke, C. (2017). A review of measures of Erikson's stages of psychosocial development: Evidence for a general factor. Journal of Adult Development, 24(1), 58-76. https://doi.org/10.1007/s10804-016-9247-4

Dvořáková, K., Kishida, M., Li, J., Elavsky, S., Broderick, P. C., Agrusti, M. R., \& Greenberg, M. T. (2017). Promoting healthy transition to college through mindfulness training with first-year college students: Pilot randomized controlled trial. Journal of American College Health: J of Ach, 65(4), 259-267. https://doi.org/10.1080/07448481.2017.1278605

Eichas, K., Meca, A., Montgomery, M. J., \& Kurtines, W. M. (2014). Identity and positive youth development: Advances in developmental intervention science. In K. McLean \& M. Syed 
EARLY ADULTS AND CONSENSUS ON LOVE

(Eds.), The Oxford Handbook of Identity Development (pp. 337-354). Oxford, UK: Oxford University Press.

Elias-Lambert, N., Black, B., \& Chigbu, K. (2014). Controlling behaviors in middle school youth's dating relationships: Reactions and help-seeking behaviors. Journal of Early Adolescence, 34(7), 841-865. https://doi.org/10.1177/0272431613510405

Embretson, S. E., \& Reise, S. P. (2000). Item response theory for psychologists. Mahwah, NJ: Erlbaum.

Erikson, E. H. (1950). Childhood and society. New York, NY, US: W W Norton \& Co.

Erikson, E. H. (1959). Growth and crisis of the healthy personality. In: Erikson EH, editor. Psychological Issues: Identity and the Life Cycle, 1 (pp. 50-100). New York: International Universities Press. https://doi.org/10.1080/21674086.1960.11926165

Erikson, E. H. (1968). Identity, youth, and crisis. New York: Norton.

Feeney, B. C. (2004). A secure base: Responsive support of goal strivings and exploration in adult intimate relationships. Journal of Personality and Social Psychology, 87, 631. https://doi.org/10.1037/0022-3514.87.5.631

Fehr, B. (1988). Prototype analysis of the concepts of love and commitment. Journal of Personality and Social Psychology, 55(4), 557-579. https://doi.org/10.1037//0022$\underline{3514.55 .4 .557}$

Fehr, B., \& Broughton, R. (2001). Gender and personality differences in conceptions of love: An interpersonal theory analysis. Personal Relationships, 8(2), 115-136. https://doi.org/10.1111/j.1475-6811.2001.tb00031.x

Finlay, A. K., Ram, N., Maggs, J. L., \& Caldwell, L. L. (2012). Leisure activities, the social weekend, and alcohol use: Evidence from a daily study of first-year college 
EARLY ADULTS AND CONSENSUS ON LOVE

students. Journal of Studies on Alcohol and Drugs, 73(2), 250-259.

https://doi.org/10.15288/jsad.2012.73.250

Fredrickson, B. L. (2013). Positive emotions broaden and build. Advances in Experimental Social Psychology, 47, 1-53. https://doi.org/10.1016/B978-0-12-407236-7.00001-2

Fredrickson, B. L. (2016). Love: Positivity resonance as a fresh, evidence-based perspective on an age-old topic. In L. F., Barrett, M. Lewis, J. M. Haviland-Jones (Eds.), Handbook of Emotions, 4th edition (847-858). New York, NY: The Guilford Press.

Gable, S. L., Reis, H. T., Impett, E. A., \& Asher, E. R. (2004). What do you do when things go right? The intrapersonal and interpersonal benefits of sharing positive events. Journal of Personality and Social Psychology, 87, 228. https://doi.org/10.1037/0022-3514.87.2.228

Gelman, A., Carlin, J. B., Stern, H. S., \& Rubin, D. B. (2013). Bayesian data analysis. Boca Raton, FL: Chapman \& Hall/CRC.

Gelman, A., \& Hill, J. (2007). Data analysis using regression and multilevel/hierarchical models (Ser. Analytical methods for social research). Cambridge University Press.

Goldscheider, F., \& Goldscheider, C. (1999). Understanding families, Vol. 17. The changing transition to adulthood: Leaving and returning home. Sage Publications, Inc.

Hendrick, C., \& Hendrick, S. S. (1986). A theory and method of love. Journal of Personality and Social Psychology, 50, 392-402. https://doi.org/10.1037/0022-3514.50.2.392

Hendrick, C. \& Hendrick S. S. (2006). Styles of romantic love. In R. J. Sternberg \& K. Weis, The new psychology of love (184-199). New Haven, CT: Yale University Press. https://doi.org/10.1017/9781108658225.012 
Heshmati, S., Blackard, B. M., Beckmann, B., Chipidza, W. (2021). Family relationships and adolescent loneliness: An application of Social Network Analysis in family studies. Journal of Family Psychology, 35(2), 182. https://doi.org/10.1037/fam0000660

Heshmati, S., Cabreros, E., I., Ellis, O., \& Blackard, M. (2021). Love and friendship across the lifespan. In Oxford Research Encyclopedia of Psychology. Oxford University Press. https://doi.org/10.1093/acrefore/9780190236557.013.746

Heshmati, S., \& Donaldson, S. I. (2020). The science of positive relationships and love. In S. I. Donaldson, M. Csikszentmihalyi, \& J. Nakamura (2nd ed.), Positive Psychological Science: Improving everyday life, well-being, work, education, and society. New York, NY: Routledge Academic.

Heshmati, S., Oravecz, Z., Brick, T. R., \& Roeser, R. W. (2020). Assessing psychological wellbeing in early adulthood: Empirical evidence for the structure of daily well-being via network analysis. Applied Developmental Science. 26(2), 207225. https://doi.org/10.1080/10888691.2020.1766356

Heshmati, S., \& Oravecz, Z. (2021). I feel loved when other people feel loved: Cultural congruence in beliefs on love is related to well-being. Journal of Social and Personal Relationships, 39(2). https://doi.org/10.1177/02654075211036510

Heshmati, S., Oravecz, Z., Pressman, S., Batchelder, W. H., Muth, C., \& Vandekerckhove, J. (2019). What does it mean to feel loved: Cultural consensus and individual differences in felt love. Journal of Social and Personal Relationships, 36(1), 214-243. https://doi.org/10.1177/0265407517724600 
Heshmati, S., Sbarra, D. A., \& Mason, A. E. (2017). The contemptuous separation: Facial expressions of emotion and breakups in young adulthood. Personal Relationships, 24(2), 453-469. https://doi.org/10.1111/pere.12192

Jakubiak, B. K., \& Feeney, B. C. (2017). Affectionate touch to promote relational, psychological, and physical well-being in adulthood: A theoretical model and review of the research. Personality \& Social Psychology Review (Sage Publications Inc.), 21(3). https://doi.org/10.1177/1088868316650307

John, O. P. (1990). The "Big Five" factor taxonomy: Dimensions of personality in the natural language and in questionnaires. In L. A. Pervin (Ed.), Handbook of personality: Theory and research (p. 66-100). The Guilford Press.

Johnson, M. (2008). Can compassion be taught? Nursing Standard, 23(11), 19-21.

Karney, B. R., \& Bradbury, T. N. (1995). The longitudinal course of marital quality and stability: A review of theory, methods, and research. Psychological Bulletin, 118(1), 3-34. https://doi.org/10.1037//0033-2909.118.1.3

Klimstra, T. (2013). Adolescent personality development and identity formation. Child Development Perspectives, 7(2), 80-84. https://doi.org/10.1111/cdep.12017

Knox, D. H. (1970). Conceptions of love at three developmental levels. The Family Coordinator, 19(2), 151-151. https://doi.org/10.2307/582445

Kuperberg, A., \& Padgett, J. E. (2016). The role of culture in explaining college students' selection into hookups, dates, and long-term romantic relationships. Journal of Social and Personal Relationships, 33(8), 1070-1096. https://doi.org/10.1177/0265407515616876 
EARLY ADULTS AND CONSENSUS ON LOVE

Kwan, V. S. Y., Bond, M. H., \& Singelis, T. M. (1997). Pancultural explanations for life satisfaction: Adding relationship harmony to self-esteem. Journal of Personality and Social Psychology, 73(5), 1038-1051. https://doi.org/10.1037//0022-3514.73.5.1038

Lamis, D., Ballard, E., \& Patel, A. (2014). Loneliness and suicidal ideation in drug-using college students. Suicide \& Life-Threatening Behavior, 44(6), 629-40. https://doi.org/10.1111/sltb.12095

Larson, R. W., Wilson, S., Brown, B. B., Furstenberg, F. F. J., \& Verma, S. (2002). Changes in adolescents' interpersonal experiences: Are they being prepared for adult relationships in the twenty-first century? Journal of Research on Adolescence, 12(1), 31-68. https://doi.org/10.1111/1532-7795.00024

Lerner, J. V., Phelps, E., Forman, Y., \& Bowers, E. P. (2009). Positive youth development. In R. M. Lerner \& L. Steinberg (Eds.), Handbook of Adolescent Psychology (3rd ed., pp. 524 558). Wiley. http://doi.org/10.1002/9780470479193

Lin, S., \& Tsai, C. (2002). Sensation seeking and internet dependence of Taiwanese high school adolescents. Computers in Human Behavior, 18(4), 411-426. https://doi.org/10.1016/S0747-5632(01)00056-5

Lodi-Smith, J., \& Roberts, B. W. (2007). Social investment and personality: A meta-analysis of the relationship of personality traits to investment in work, family, religion, and volunteerism. Personality and Social Psychology Review, 11, 68-86. https://doi.org/10.1177/1088868306294590

Magis-Weinberg, L., Gys, C. L., Berger, E. L., Domoff, S. E., \& Dahl, R. E. (2021). Positive and negative online experiences and loneliness in Peruvian adolescents during the covid-19 
EARLY ADULTS AND CONSENSUS ON LOVE

lockdown. Journal of Research on Adolescence: The Official Journal of the Society for Research on Adolescence, 31(3), 717-733. https://doi.org/10.1111/jora.12666

Manzeske, D. P., \& Stright, A. D. (2009). Parenting styles and emotion regulation: the role of behavioral and psychological control during young adulthood. Journal of Adult Development, 16(4), 223-229. https://doi.org/10.1007/s10804-009-9068-9

Masten, A. S., Burt, K. B., Roisman, G. I., Obradović, J., Long, J. D., \& Tellegen, A. (2004). Resources and resilience in the transition to adulthood: Continuity and change. Development and Psychopathology, 16(4), 1071-94. https://doi.org/10.1017/s0954579404040143

MATLAB. (2010). version 7.10.0 (R2010a). Natick, Massachusetts: The MathWorks Inc.

McConnell, E. (2015). Compassion starts from within: Beyond the checklist. Nursing and Residential Care, 17(2), 96-99. https://doi.org/10.12968/nrec.2015.17.2.96

Montgomery, M. J. (2005). Psychosocial intimacy and identity: From early adolescence to emerging adulthood. Journal of Adolescent Research, 20(3), 346-374. https://oi.org/10.1177/0743558404273118

Mund, M., \& Johnson, M. D. (2021). Lonely me, lonely you: Loneliness and the longitudinal course of relationship satisfaction. Journal of Happiness Studies: An Interdisciplinary Forum on Subjective Well-Being, 22(2), 575-597. https://doi.org/10.1007/s10902-020$\underline{00241-9}$

Neto, F., \& Wilks, D. C. (2017). Compassionate love for a romantic partner across the adult life span. Europe's Journal of Psychology, 13(4), 606-617. https://doi.org/10.5964/ejop.v13i4.1204 
Noller, P., Feeney, J. A., \& Peterson, C. (2001). Personal relationships across the lifespan. New York: Brunner-Routledge.

Oravecz, Z., Anders, R., \& Batchelder, W. H. (2015b): Hierarchical Bayesian modeling for test theory without an answer key. Psychometrika, 80, 341-364. https://doi.org/10.1177/1525822X13520280

Oravecz, Z., Dirsmith, J., Heshmati, S., Vandekerckhove, J., \& Brick, T. R. (2020). Psychological well-being and personality traits are associated with experiencing love in everyday life. Personality and Individual Differences, 153, 109620. https://doi.org/10.1016/j.paid.2019.109620

Oravecz, Z., Faust, K., Batchelder, W. H., \& Levitis, D. (2015a). Studying the existence and attributes of consensus on psychological concepts by a cognitive psychometric model. The American Journal of Psychology, 128, 61-75. https://doi.org/10.5406/amerjpsyc.128.1.0061

Oravecz, Z., Muth, C., \& Vandekerckhove, J. (2016). Do people agree on what makes one feel loved? A cognitive psychometric approach to explore consensus on felt love. PLoS ONE, 11. https://doi.org/10.1371/journal.pone.0152803

Oravecz, Z., \& Vandekerckhove, J. (2020). A joint process model of consensus and longitudinal dynamics. Journal of Mathematical Psychology, 98, [102386]. https://doi.org/10.1016/j.jmp.2020.102386

Over, H. (2016). The origins of belonging: Social motivation in infants and young children. Philosophical Transactions: Biological Sciences, 371(1686), 1-8. https://doi.org/10.1098/rstb.2015.0072 
EARLY ADULTS AND CONSENSUS ON LOVE

Pew Research Center. Social Media Update 2014.2015. Available at: http://www.webcitation.org/6ajEhvS11.

Plummer, M. (2003, March). JAGS: A program for analysis of Bayesian graphical models using Gibbs sampling. In Proceedings of the 3rd international workshop on distributed statistical computing (Vol. 124, p. 125). Wien, Austria: Technische Universit at Wien.

Qualtrics XM // The Leading Experience Management Software. (n.d.). Retrieved from https://www.qualtrics.com/

Reis, H. T., \& Aron, A. (2008). Love: What is it, why does it matter, and how does it operate? Perspectives on Psychological Science, 3(1), 80-86. https://doi.org/10.1111/j.1745$\underline{6916.2008 .00065 . x}$

Reis, H. T., Clark, M. S., \& Holmes, J. G. (2004). Perceived partner responsiveness as an organizing construct in the study of intimacy and closeness. In D. Mashek \& A. Aron (Eds.), The handbook of closeness and intimacy (pp. 201-225). Mahwah, NJ: Lawrence Erlbaum Associates.

Reis, H., Collins, W., \& Berscheid, E. (2000). The relationship context of human behavior and development. Psychological Bulletin, 126, 844-872. https://doi.org/10.1037/0033$\underline{2909.126 .6 .844}$

Robins, R. W., Fraley, R. C., Roberts, B. W., \& Trzesniewski, K. H. (2001). A longitudinal study of personality change in young adulthood. Journal of Personality, 69(4), 617-40. https://doi.org/10.1111/1467-6494.694157

Rokach, A. (2018). How are love, loneliness, and health related? Psychology and Psychotherapy: Research Study, 1. https://doi.org/10.31031/PPRS.2018.01.000521 
EARLY ADULTS AND CONSENSUS ON LOVE

Romney, A. K., Batchelder, W. H. (1999). Cultural consensus theory. In Wilson, R., Keil, F. (Eds.), The MIT encyclopedia of the cognitive sciences (pp. 208-209). Cambridge, MA: The MIT Press.

Romney, A. K., Weller, S. C., \& W. H. Batchelder. (1986). 'Culture as consensus: A theory of culture and informant accuracy. American Anthropologist 88(2):313-38. https://doi.org/10.1525/AA.1986.88.2.02A00020

Rotenberg, K. J., Addis, N., Betts, L. R., Corrigan, A., Fox, C., Hobson, Z., Rennison, S., Trueman, M., \& Boulton, M. J. (2010). The relation between trust beliefs and loneliness during early childhood, middle childhood, and adulthood. Personality \& Social Psychology Bulletin, 36(8), 1086-100.

Rubin, Z. (1988). Preface. In R. J. Sternberg and M. L. Barnes (Eds.), The Psychology of Love (pp. 7-12). New Haven Conn: Yale University Press.

Schmitt, D. P. (2004). Patterns and universals of mate poaching across 53 nations: The effects of sex, culture, and personality on romantically attracting another person's partner. Journal of Personality and Social Psychology, 86, 560. https://doi.org/10.1037/0022-

\subsubsection{0}

Schmitt, D., Youn, G., Bond, B., Brooks, S., Frye, H., Johnson, S., . . Stoka, C. (2009). When will I feel love? The effects of culture, personality, and gender on the psychological tendency to love. Journal of Research in Personality, 43(5), 830-846. https://doi.org/10.1016/j.jrp.2009.05.008

Schulenberg, J. E., Sameroff, A. J., \& Cicchetti, D. (2004). The transition to adulthood as a critical juncture in the course of psychopathology and mental health [Editorial]. 
EARLY ADULTS AND CONSENSUS ON LOVE

Development and Psychopathology, 16(4), 799-806. https://doi.org/10.1017/S0954579404040015

Seiffge-Krenke, I. (2003). Testing theories of romantic development from adolescence to young adulthood: Evidence of a developmental sequence. International Journal of Behavioral Development, 27, 519-531. https://doi.org/10.1080/01650250344000145

Shaver, P. R., \& Brennan, K. A. (1992). Attachment styles and the "big five" personality traits: Their connections with each other and with romantic relationship outcomes. Personality and Social Psychology Bulletin, 18(5), 536-545. https://doi.org/10.1177/0146167292185003

Soto, C., \& John, O. (2017). Short and extra-short forms of the Big Five Inventory-2: The BFI-2S and BFI-2-XS. Journal of Research in Personality, 68, 69-81. https://doi.org/10.1016/j.jrp.2017.02.004

Soto, C., John, O., Gosling, S., \& Potter, J. (2011). Age differences in personality traits from 10 to 65: Big Five domains and facets in a large cross-sectional sample. Journal of Personality and Social Psychology, 100(2), 330-48. https://doi.org/10.1037/a0021717

Sprecher, S., \& Fehr, B. (2005). Compassionate love for close others and humanity. Journal of Social and Personal Relationships, 22(5), 629-

651. https://doi.org/10.1177/0265407505056439

Sternberg, R. J. (1986). A triangular theory of love. Psychological Review, 93, 119- 135. https://doi.org/10.1037/0033-295X.93.2.119

Sternberg, R. J. (2006). A duplex theory of love. In R. J. Sternberg \& K. Weis (Eds.), The new psychology of love (pp. 184-199). New Haven, CT: Yale University Press. 
EARLY ADULTS AND CONSENSUS ON LOVE

Sternberg, R. J., \& Sternberg, K. (2019). The new psychology of love (2 ${ }^{\text {nd }}$ ed.). Cambridge University Press.

Tsai, C., \& Lin, S. (2003). Internet addiction of adolescents in Taiwan: An interview study. Cyberpsychology \& Behavior, 6(6), 649-652. https://doi.org/10.1089/109493103322725432

Walker, K., Sleath, E., \& Tramontano, C. (2021). The prevalence and typologies of controlling behaviors in a general population sample. Journal of Interpersonal Violence, 36(1-2), 503. https://doi.org/10.1177/0886260517731785

Weller, S. C. (2007). Cultural Consensus Theory: Applications and Frequently Asked Questions. Field Methods, 19(4), 339-368. https://doi.org/10.1177/1525822X07303502

Wilcox, H. C., Arria, A. M., Caldeira, K. M., Vincent, K. B., Pinchevsky, G. M., \& O'Grady, K. E. (2010). Prevalence and predictors of persistent suicide ideation, plans, and attempts during college. Journal of Affective Disorders, 127, 287- 294.

https://doi.org/10.1016/j.jad.2010.04.017 